\title{
A study of leprosy patients with deformities, and the implications for the treatment of all leprosy patients*†
}

\author{
JANET E PRICE \\ 70 Harcourt Road, Sheffield 10, England
}

Received for publication 29 September 1982

\begin{abstract}
Summary The attendance of leprosy patients with grade 2 and 3 deformities for treatment and physiotherapy care at clinics run by the Bombay Leprosy Project (BLP) in the slums of the city was very poor. A survey was conducted to try and discover what factors might affect attendance. This showed that many patients had misconceptions about the disease and their deformity. The clearer their understanding, the more motivated they were to attend for treatment.

Appropriate education to improve knowledge about the disease may play a large part in motivating all patients, including those with deformities, to take treatment. To carry out this education effectively necessitates an understanding by leprosy workers of local attitudes and ideas about the disease.
\end{abstract}

The Bombay Leprosy Project (BLP) is an urban leprosy control group working in the slums of the city. In accordance with the Government-designated SET (survey-education-treatment) scheme they run clinics, conduct house-to-house surveys and do educational work. They also provide physiotherapy care and advice to those patients with deformities. This is available at both treatment and separate physiotherapy clinics. A few home visits are also made. Services offered include demonstration of massage and exercises, ulcer care, and provision of splints, aids and footwear. However, patient response to both physiotherapy and drug treatment was poor.

We carried out a survey of grade 2 and 3 patients registered with the project to investigate the factors that might influence their response to treatment with the aid of improving the care received. The areas of study included:

(a) Demographic and socio-economic data to provide background information about the group studied.

* This study was conducted under the auspices of Dr R Ganapati, Director, the Bombay Leprosy Project (BLP) and on a student sponsorship with LEPRA, the British Leprosy Relief Association.

$\dagger$ A full copy of the report (37 pages) is available on request. Please cover costs of photocopying. 
(b) Objective assessment and history of the disease and deformity.

(c) Patient's attitude to the disease, deformity and care offered: (i) Knowledge of and attitude towards leprosy and its treatment, to assess the clarity of the patient's concept of the disease. (ii) A comparable study of knowledge and attitude to the deformity and its care. (iii) The effect of the deformity upon the patient's life.

\section{Method}

\section{(a) SAMPLE GROUP}

Of 301 grade 2 and 3 patients registered with BLP, 259 were eligible for the study. (The remainder refused treatment or could not be traced in the slum areas.) A sample group of 91 was taken. Although no statistical sampling method was used, attempts were made to contact all patients; but due to the difficulties this entailed, the sample is biased towards those who attend clinics (Table 1).

(b) DATA

Baseline data was collected from project records. Primary data was collected by means of a questionnaire, compiled in English and directly translated into the native language of each respondent. This was necessary as there is no common

Table 1. Patient attendance for medical (drug) and physiotherapy care

\begin{tabular}{|c|c|c|c|c|}
\hline & \multicolumn{2}{|c|}{$\begin{array}{l}\text { All registered } \\
\text { patients }\end{array}$} & \multicolumn{2}{|c|}{ Sample group } \\
\hline & No. & $(\%)$ & No. & $(\%)$ \\
\hline $\begin{array}{l}\text { Frequent* attendance for medical and } \\
\text { physiotherapy care (seen in } 6 / 12 \text { or more) }\end{array}$ & 43 & 14 & 39 & $42 \cdot 9$ \\
\hline $\begin{array}{l}\text { Frequent attendance for medical care, } \\
\text { infrequent attendance for physiotherapy }\end{array}$ & 153 & $51 \cdot 0$ & 31 & $34 \cdot 1$ \\
\hline $\begin{array}{l}\text { Infrequent attendance for medical care, } \\
\text { frequent attendance for physiotherapy }\end{array}$ & 3 & $1 \cdot 0$ & 1 & $1 \cdot 1$ \\
\hline $\begin{array}{l}\text { Infrequent attendance for medical and } \\
\text { physiotherapy care }\end{array}$ & 102 & $34 \cdot 0$ & 19 & $20 \cdot 9$ \\
\hline Total & 301 & $100 \cdot 0$ & $90 \dagger$ & $99 \cdot 0$ \\
\hline
\end{tabular}

* 'Frequent' indicates patients were seen in at least 6 months of the year. $\dagger$ Plus 1 just registered $=91$. 
language amongst the patients who migrate to the Bombay slums from all over India.

\section{Results}

(a) DEMOGRAPHIC AND SOCIO-ECONOMIC DATA

The group consisted of 66 males and 25 females. Their ages covered a wide range: only a small number were children under 15 years (6) and old people (6). They had a very low socio-economic status, the majority living in slum-style accommodation and existing on or below the poverty line. Although $80 \%$ were of an age commensurate with regular employment, only about half had a permanent occupation and many of these earned a non-living wage.

The standard of general education was also low, just under half (39) having received no formal education of any type, approximately one-third (32) having studied for less than 5 years, and only 4 having completed more than 10 years' education.

\section{(b) DISEASE}

They were mainly long-term sufferers. Sixty-five per cent had known of their disease for more than 5 years, their deformities developing subsequently. Seventy-seven per cent attended fairly frequently for medical treatment but response to physiotherapy care was not as good, only $20 \%$ receiving regular advice and a further $20 \%$ being seen irregularly but in more than 6 months of the year (Table 1).

(c) KNOWLEDGE AND ATTITUDE TO DISEASE AND DEFORMITY

\section{(i) Cause}

We wanted to assess how aware the patients were of the true facts about leprosy. Their beliefs as to its cause could be classified into 5 major groups (Table 2). Even though most patients had been suffering from leprosy for a number of years very few had any correct notion as to its cause. However only a third had fixed, incorrect views $(\mathrm{A}, \mathrm{B}, \mathrm{C})$ and a large proportion were undecided. Their general educational standard appears to be associated with their beliefs, a higher level eliminating the superstitious beliefs such as a curse of God, and leading to the idea of cause and effect, i.e. that specific actions, such as alcohol consumption, lead to leprosy. More informed notions such as germs were associated with higher levels again.

The respondents were also asked what they believed had caused their 
Table 2. Patients' beliefs of cause of leprosy, and level of general education

\begin{tabular}{|c|c|c|c|c|c|c|c|}
\hline & \multirow[b]{2}{*}{ Belief } & \multicolumn{4}{|c|}{ Education } & \multirow[b]{2}{*}{ Total } & \multirow{2}{*}{$\begin{array}{c}\text { Percentage } \\
\text { of } \\
\text { patients }\end{array}$} \\
\hline & & Nil & $\begin{array}{l}1-5 \\
\text { Std }\end{array}$ & $\begin{array}{c}6-10 \\
\text { Std }\end{array}$ & $\begin{array}{c}\mathrm{SSC}^{*} \\
\text { pass }\end{array}$ & & \\
\hline A & 'Superstitious' beliefs & 12 & 5 & - & - & 17 & $18 \cdot 7$ \\
\hline B & Results of life-style & 4 & 3 & 2 & 1 & 10 & $11 \cdot 0$ \\
\hline $\mathrm{C}$ & Hereditary & 1 & 4 & - & - & 5 & $5 \cdot 5$ \\
\hline $\mathrm{D}(\mathrm{i})$ & Informed notions: (a) germs & 3 & 3 & 5 & 2 & 13 & $14 \cdot 3$ \\
\hline D(ii) & (b) Contact with patients & 5 & 7 & 1 & - & 13 & $14 \cdot 3$ \\
\hline $\mathrm{E}$ & Do not know & 15 & 13 & 6 & 3 & 37 & $40 \cdot 7$ \\
\hline Total & & $\overline{40}$ & $\overline{35}$ & $\overline{14}$ & $\overline{6}$ & $\overline{95 \dagger}$ & $\overline{-}$ \\
\hline
\end{tabular}

* SSC-School Certificate.

$\dagger$ The total is greater than in the sample group as 4 patients gave more than one response.

deformity (Table 3). About $40 \%$ accepted that their deformity was due to leprosy, but a high proportion attributed it to other factors. Reasons given included burns, wearing a tight ring, and 2 young girls attributed it to decorating their hands with henna. Thus many patients felt that they were suffering from two unconnected complaints: leprosy, and their physical handicap.

Table 3. Patients' beliefs about the cause of their deformity

\begin{tabular}{lc}
\hline \multicolumn{1}{c}{ Belief } & No. of respondents \\
\hline Leprosy & 37 \\
Negligence & 6 \\
Physical damage/accident & 22 \\
Burns & 9 \\
Automatically & 14 \\
Do not know & 2 \\
Other & 5 \\
\cline { 2 - 2 } Total & $95^{*}$ \\
\hline
\end{tabular}

* Four patients gave more than one cause for their deformity. 


\section{(ii) Cure}

Almost all respondents (80/91) said that leprosy was curable, 6 were uncertain and 5 did not believe a cure was possible.

We asked patients about the curability of their deformity and ways in which this could be achieved to discover whether they were a group who felt that their disability was permanent or whether they would react positively towards treatment in the belief that it would be of some benefit to them. Their feelings about the permanence of their handicap would also affect their psychological reactions towards it.

About $90 \%$ (81) expressed the view that their deformity was curable. Twenty-six per cent felt that tablets on their own would effect a cure, $24 \%$ believed a combination of tablets and physiotherapy as necessary and $37 \%$ had faith in physiotherapy alone. In total, more than $60 \%$ expressed a belief in the benefit of physiotherapy. A small number felt that the deformity would disappear of its own accord or that some other remedy such as native leaf juices would help. Only 8 said that their deformity was not curable, and 2 had no definite view.

We compared patients' beliefs about the nature of cure with their concepts about the cause of their deformity. Those who accepted that it was due to leprosy had a greater confidence in physiotherapy (with or without tablets). Those who attributed it to other causes had equal confidence in tablets and physiotherapy.

\section{(iii) Advice}

Patients were questioned about the advice they had been given and whether they had experienced any improvement in their condition with physiotherapy (Table 4). They remembered most clearly that advice which could be demonstrated and

Table 4. Care/advice that patients remembered

\begin{tabular}{lc}
\hline Care remembered & No. of patients \\
\hline Health education & 44 \\
Massage & 84 \\
Exercises & 72 \\
Ulcer care & 30 \\
Operation & 3 \\
Aids/footwear & 29 \\
& $*$ \\
\hline
\end{tabular}

* Patients recorded all types of care given: total is greater than 91 . 
which they could practise in clinic in the presence of a worker, i.e. massage and exercises. Health education and information about the dangers associated with their deformity would have been given to all registered patients, but their recollection of spoken advice and acceptance of new ideas was not good. (This is supported by the small number who held informed ideas about the disease and deformity.)

Seventy per cent said there had been some improvement in their deformity with physiotherapy care. Fewer had previously expressed a belief that physiotherapy would cure their deformity $(60 \%)$ and an even smaller number said they followed advice regularly. A greater proportion of this latter group attributed their deformity to leprosy rather than to other causes. This suggests that they may have had a clearer concept of their illness and so were better motivated to follow advice.

\section{(iv) Emotional reactions}

In view of the great stigma attached to leprosy we felt that the patients' emotional reaction might be of importance in their motivation to take advice. In addition, although it is often assumed that a handicap will cause some physical difficulty, less attention is paid to the possible psychological effects on the individual. Over $70 \%$ felt either worry, shame, embarrassment or a combination, whilst just under $30 \%$ did not admit to any problem. (Only 53\% said that they experienced physical difficulties.) They gave various reasons for their concern (Table 5).

Although a large number of respondents experienced psychological problems connected with their deformity, only about half of them were disturbed because of the association between their handicap and leprosy and fear of the attached stigma. Many did not connect the two and suffered mentally purely because of their physical imperfection. It is well known that the physically handicapped may

Table 5. Reasons for patients' concern about their deformity

\begin{tabular}{lc}
\hline \multicolumn{1}{c}{ Reason } & No. of patients \\
\hline Shame/embarrassment of physical imperfection & 11 \\
Fear that people would ask about the deformity & 11 \\
Fear that people would know of disease by & 15 \\
$\quad$ seeing deformity & 10 \\
Problems with work & 7 \\
Concern about the future & 11 \\
Other/unable to explain & 26 \\
Unconcerned & 91 \\
Total & 91 \\
\hline
\end{tabular}


find it difficult to readjust and alter their body image to come to terms with their physical imperfection and it is important to remember in dealing with deformity cases that this will be a problem experienced by all of them, whilst a much smaller number will actually have fears connecting their deformity and the stigma of leprosy.

We also looked at the extent and degree of their deformity to see whether this affected their reactions. Minor degrees of handicap caused few problems, but as they became more noticeable the patients experienced greater fears. They reacted more strongly to hand deformities which were less easy to disguise, and for which it was more difficult to find plausible excuses, than to feet deformities which could be hidden by footwear or explained away in terms of physical trauma. However, when their deformities became very extensive and impossible to disguise some patients became resigned to them. They knew that people would be able to identify them as sufferers from leprosy and the uncertainty and fear which afflicted the less severely handicapped had been removed. They had been able to readjust and accept a new body image, realizing their deformity was permanent, in contrast to others who had hopes of a cure and so were not able to establish a clear and constant image of themselves.

\section{Conclusion}

It appears from these results that reactions to handicap are determined by the concepts patients hold about the disease and that these affect motivation and response to treatment.

Those patients who admit that their deformity is due to leprosy are more likely to: (a) believe physiotherapy will help cure it; (b) say that they are regular in following physiotherapy advice; and (c) attend a physiotherapy clinic frequently, believing it will cure the deformity. They are also more likely to attend regularly for medical treatment. The incidence of psychological problems is the same amongst these as other patients but a larger proportion are concerned or fearful due to reasons linked with leprosy. This group appears to have a fairly clear understanding of their disease. They accept that regular drug treatment is necessary to cure leprosy but realize the additional benefits of physiotherapy. A large number, being better informed about the disease and more conscious of its possible social implications, are also frightened and worried about it. They fear the stigma that may be attached to them if others come to know of their disease. Others have overcome this fear and with their clearer knowledge are willing to admit openly to others that they are suffering.

A large group of cases appear to be confused in their understanding. They do not believe leprosy caused their deformity, giving a variety of other reasons for it, and they are not clear as to the ways in which drug treatment and physiotherapy can help them. 
Finally there is a small pool of sufferers who are totally unconcerned about their disease and physical problems, or who have no faith in treatment. They usually constitute those with the severer grade of deformity for whom it is much more difficult to give constructive advice. They have become resigned to their handicap, believing that nothing will restore the function of their hands and feet, and so do not accept or follow physiotherapy advice. They are also irregular for medical treatment feeling that there is little point in taking drugs to cure a disease which has already affected them so severely and irreversibly.

This study was carried out amongst a normal slum population in Bombay. However, around the city there is also a large number of leprosy sufferers with def ormities who survive by begging. They tend to live in pavement slum dwellings or in leprosy colonies, and are often unwilling to take treatment or advice, as their deformities represent their source of livelihood.

That response to treatment appears to be linked with patients' concepts of the disease and their total health awareness holds implications for the treatment of all leprosy sufferers not just those with deformities. The fact that such a large proportion of patients who have suffered and been treated for many years do not have even a basic knowledge of the cause of the disease indicates that the dissemination of information is very poor. This could be due to an inadequate approach to education by the various organizations who provide care. It is also possible that there is only a core of individuals who have been able to adjust to and accommodate new ideas, the remainder being unmoved from their pre-existing patterns of thought and belief.

It would be interesting to compare these findings with studies of patients' response to other 'chronic' diseases for which people must take long-term treatment, that have gradually progressive physical effects which often do not appear to be related to the actual complaint, e.g. diabetes, or cardiac failure in hypertensive people. The physical signs of leprosy are much more distinctive and stigmatizing than in all other diseases, but the problem of long-term treatment for what may appear to be an 'asymptomatic' illness, and associated care for seemingly unconnected physical problems is not a unique one.

Great emphasis needs to be laid upon education, and the way in which facts are presented is of great importance. The physiotherapy advice that patients remembered was that which was demonstrable, i.e. massage and exercises-and this had the greatest impact. A greater use of visual aids in presenting facts about the disease may be of value in helping them to grasp new concepts and to clarify their views. Greater attempts should be made to present the material in a way that is culturally acceptable to the people, taking into account their existing beliefs, rather than working from the basis of a scientific background which they may not accept. Leprosy workers should be aware of local attitudes and ideas about the disease. Although educating patients in the early stages of treatment when they first come into contact with the care organization may be time-consuming and staff-intensive, this survey suggests that the benefits to patients in terms of clearer 
understanding of the disease, better compliance with treatment and hence, ultimate cure, may be invaluable.

\section{Acknowledgements}

I wish to thank Mr P R Dewarkar and Miss Clara Rodrigues, paramedical workers with BLP, for help in compiling the questionnaire, and presenting it to respondents; Dr C R Revenkar for his advice; and Mrs Indira Kotval for help in analysing the results and writing the full report.

\section{Further reading}

Background data and parts of questionnaire from: R K Mutatkar, Society and Leprosy (Shubhada-Saraswat, Pune). 